\title{
AVALIAÇÃO DE DANOS DE Sitophilus zeamais MOTSCHULSKY, 1855 EM GRÃOS DE SORGO COM GLUMA, INTEIROS LIMPOS E LIMPOS QUEBRADOS EM CONDIÇÕES DE LABORATÓRIO
}

\author{
J.M. WAQUIL ${ }^{1}$ O. NAKANO ${ }^{2}$
}

\begin{abstract}
Estimation of damage of Sitophizus zeamais Motschulsky, 1855 in sorghum grains with glumes, whole grains, and broken grains under laboratory conditions
\end{abstract}

Brazil is recognized as a potentially great producer of sorghum for the world market. However, this cereal is highly susceptible to attack by insect pests. This study attempted to estimate the damage caused to sorghum grain by Sitophizus zeamais Motschulsky, 1855 (Coleop tera: Curculionidae); the susceptibility of two genotypes of grains with glumes, whole grains and broken grains was evaluated. The suscep tibility of three types of DK E57 hybrid grains and of strain Cont-75 grains was studied by confining 0, 10, 30 and 60 adult weevils in $20 \mathrm{~g}$ of grains of each types for 30 days. Whole grains appeared to be more susceptible at all levels of infestation studied. At low infestations, grains with glumes were less susceptible than broken grains, but at high infestation levels, the broken grains were less susceptible and produced lighter insects.

\section{INTRODUÇÃO}

A cultura do sorgo vem recebendo grande estimulo no Brasil e apesar de poucos dados a respeito, estima-se que em 1976/77 a área plan tada tenha sido em torno de $420 \mathrm{mil}$ ha. Dentre os problemas que afetam a cultura do sorgo, destacam-se as pragas como um dos principais. Se gundo ROSSETTO et a $i$ i (1972), embora existam dezenas de espécies de in setos que possam infestar o sorgo armazenado, três são as principais responsáveis pelos danos, sendo muito dificil definir qual delas seria a mais importante: traça dos cereais - Sitotroga cerealeZZa (olivier, 1819), gorgulho do sorgo e trigo - Sitophilus oryzae (Liné, 1763) e gor gulho do milho - Sitophilus zeamais Motschulsky, 1855. Dos gorgulhos, a espécie mais difundida no Brasil, segundo ROSSETTO (1972), és. zecomais, assumindo assim maior importância para as nossas condições.

Recebido em 27/11/78.

${ }^{1}$ Pesquisador do Centro Nacional de Pesquisa de Milho e Sorgo - EMBRAPA.

${ }^{2}$ Professor Adjunto do Departamento de Entomologia - ESALQ/USP. 
PARKIN (1956) fez uma extensa revisão a respeito dos danos cau sados por insetos aos produtos armazenados. Ele distingue dois tipos de estimativas de danos: estimativas gerais e estimativas experimentais. Afirma ainda que os danos nos produtos armazenados ocorrem com maior in tensidade nos países tropicais e sobretudo nos subdesenvolvidos onde um desconhecimento geral do problema figura como a causa principal.

Os gräos de cereais podem vir do campo já infestados por inse tos; assim, RUSSELL (1962 a) relata a infestação do milho no campoKIRITANE (1965) afirma que o S. zeamais infesta os grãos de cereais no campo mais frequentemente que o $S$. oryzae, pois possui maior capacidade de vôo que este. RITCHE (1925-26) afirma que os grãos de sorgo do tipo macio são atacados no campo pela $S$. cerealella e $S$. orizae e que essas duas espécies são aparentemente atraídas por panículas do tipo fechada.

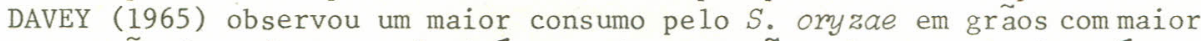
proporção de endosperma farináceo e desses grãos obteve um maior número de progênies, em casos extremos até 20:1. A dureza dos grãos, espessu ra do endosperma vítreo, presença de glumas, são citados como fatores de resistência por SAMUEL \& CHATTERJI (1953), DOGGETT (1957, 1958), RUSSELL (1962, a e b, 1966), TEOTIA \& SINGH (1968) e SINHA (1971). ROGERS \& MILLS (1974) testaram a coleção mundial para resistência ao $S$. zeamais e verificaram que sementes com glumas totalmente fechadas foram totalmente resistentes aos gorgulhos.

Com relação a grãos quebrados, REDDY (1950) e MORRISON (1964) observaram que fểmeas do gorgulho preferem ovipositar em grãos intei ros, somente quando estes estão misturados, sendo possível a escolha. LEFEVRE (1953), estudando os danos de S. oryzae em sorgo, através de amostragens num período de 12 meses, observou que o maior decréscimo de grãos sadios, em dois armazens, ocorreu do terceiro para o sexto mês de estocagem, quando a incidência de adultos passou de 90 para 710 gorgu lhos por amostragem. Entretanto, o maior incremento da perda de peso ocorreu do nono para o décimo mếs, quando a incidência de insetos adul tos passou de 830 para 1.000. YADAV et alii (1968) observaram que la vas de $S$. oryzae alimentando-se por 15 dias em sementes de sorgo, fazem com que elas percam totalmente a germinação.

A colheita do sorgo é feita geralmente através de combinadas au tomotrizes. A massa de grãos obtida dessa forma é composta por uma mi $\underline{\underline{s}}$ tura de grãos inteiros, inteiros com glumas e quebrados sendo que a pró porção dessas três categorias depende da regulagem da colhedeira e do teor de umidade dos grãos. No presente trabalho, procurou-se estimar as perdas ocorridas devido ao ataque do $S$. zeamais a essas três diferentes categorias de grãos.

\section{MATERIAIS E METODOS}

O experimento foi conduzido no laboratório de biologia do Depar tamento de Entomologia da ESALQ da USP no ano de 1976. Os grãos de soŕ go utilizados, tanto na criação dos insetos como na montagem do experí mento, foram de dois genótipos: da linhagem Cont-75 e do hỉbrido Dekalb $\mathrm{E}_{57^{\circ}}$

Os insetos utilizados na infestação, S. zecmais confirmados pe- 
la observação da genitälia, foram criados em sorgo a partir de uma pe quena população jâ existente no Departamento, segundo o método preconí zado por ROSSETTO (1972 b).

Utilizou-se como recipiente, nos experimentos, potinhos plásti $\cos$ com 4,5 cm de diâmetro e $8 \mathrm{~cm}$ de altura os quais possuiam tampa de pressão. Estas foram furadas e revestidas internamente com tela fina de nylon.

Para as pesagens utilizou-se uma balança METTLER $H_{10}$ com preci são de $0,1 \mathrm{mg}$ e para as determinações de umidade de grãos utilizou-se o método de estufa.

Nas contagens de insetos utilizou-se de uma bomba de väcuo, ajustada para sucção a um sistema de dois Erlenmeyers ligados por tubos de borracha. Um Erlenmeyer permanecia com óleo lubrificante para reter a poeira e no outro se coletava os insetos.

As três classes de grãos estudadas foram separadas manualmente de um lote de grãos. Os gräos com glumas e inteiros limpos foram esco 1hidos e os quebrados foram obtidos partindo-se longitudinalmente ao meio gräos inteiros limpos.

Foram pesados $20 \mathrm{~g}$ de grãos com $0,1 \mathrm{mg}$ de precisão e colocados nos potinhos plásticos. No caso dos grãos com glumas, o peso destas foi descontado na base de $12,76 \%$ para o híbrido e $12,87 \%$ para a linha gem. Estes dados representam a média de quatro amostras de 25 grãos cāa da, as quais apresentaram coeficientes de variação da ordem de $1,91 \% \overline{\mathrm{e}}$ $9,57 \%$ respectivamente.

Adotou-se o delineamento em Fatorial em três repetições com os seguintes tratamentos:

a) 4 niveis de infestação $(0,10,30$ e 60 insetos)

b) 3 tipos de grãos (com glumas, limpos e quebrados)

c) 2 genótipos (Dekalb E57 e Cont-75).

As parcelas foram infestadas no dia 4 de agosto nos diferentes niveis, utilizando-se insetos adultos tomados ao acaso em uma colonia com 40 a 45 dias de idade. Apōs a infestação, os potinhos foram acondi cionados ao acaso dentro de três caixas de papelão. As caixas foram cō bertas com pano preto para evitar a entrada de luz. No mesmo dia as cai xas foram colocadas na sala onde a umidade e temperatura eram registra das por um termohigrógrafo.

Depois de 30 dias, as parcelas foram peneiradas cinco vezes, com intervalos de sete dias para se obter o nümero total de insetos desen volvidos em cada parcela. Após cada contagem, os insetos de cada parcé la foram pesados com precisão de $0,1 \mathrm{mg}$ e dividindo-se o peso pelo númé ro de insetos, obteve-se o peso mêdio dos mesmos. o indice de emergên cia foi calculado dividindo-se o número de insetos emergidos na parcela pelo número de insetos utilizados na infestação da respectiva parcela. A porcentagem de insetos emergidos nas duas primeiras contagens (1 1 + 2a), foi obtida em função do número total de insetos emergidos na res pectiva parcela.

Em seguida à ültima contagem, realizada no dia 2 de outubro de 1976, os grãos peneirados foram pesados e tiveram sua umidade determina da pelo método de estufa. O peso final dos grãos de cada parcela foi corrigido para a umidade inicial e as porcentagens de perda de peso fo ram determinadas. 
A anālise estatística foi realizada no Centro de Computação Ele trônica do Departamento de Matemätica e Estatística da ESALQ.

\section{RESULTADO E DISCUSSÃO}

Das cinco contagens de insetos realizadas, na primeira não se observou insetos da segunda geração. Portanto para comparação da prole, foram computadas apenas quatro contagens ao invés de cinco.

0 resultado da análise de variância está representado pelos res pectivos quadrados médios, os quais foram comparados pelo teste de "F" e estão apresentados no Quadro 1. Como pode ser observado, encontrou-se diferença significativa entre os genótipos só para porcentagem de inse tos emergidos até a 2 a contagem. No entanto para os outros tratamentos encontrou-se diferença significativa para todos os parâmetros compara dos.

No Quadro 2 está a comparação das médias quando se estudou o efeito do nível de infestação. Verificou-se que o único parâmetro que não foi afetado por este tratamento foi o peso médio dos insetos. Quan to ao índice de emergência, caiu significativamente a partir da infesta ção com 10 insetos, mostrando já uma alta competição intraespecífica nesse nível de infestação. Para o mesmo inseto em milho, essa competi ção ocorre a partir de 15 casais em 20 grãos da variedade Maia Opaco, apresentada por SILVEIRA NETO et alii (1976). A porcentagem de insetos emergidos até a 2 a contagem aumentou, mostrando um menor ciclo de desen volvimento, mas isto se deve provavelmente ao aumento de temperatura de vido a atividade de um maior número de larvas. Embora não se tenha ré gistrado a temperatura dentro de cada parcela, essa elevação de temperá tura já foi reportada por KIRITANE (1965). Quanto a perda de peso dos grãos é evidente o seu incremento com o aumento do nümero de insetos usados na infestação, mas o dano atribuído a cada inseto é maior nas in festações com menor nümero de insetos.

o tipo de grão afetou todos os parâmetros estudados, (Quadro 3). 0 peso médio dos insetos emergidos foi significativamente menor nos grãos quebrados, o que concorda em parte com RUSSELL (1962 b) quando ob servou a emergência de insetos mais leves de grãos menores. Isto se de ve provavelmente a uma menor disponibilidade de alimento.

Quanto ao número total de insetos emergidos, índice de emergên cia, porcentagem de insetos emergidos até $2 \underline{a}$ contagem e porcentagem de perda de peso, foram menores nos grãos com glumas. Portanto, as glu mas, mesmo não sendo do tipo totalmente fechadas como descrevem ROGERS \& MILLS (1974), oferecem uma certa proteção aos grãos contra o ataque de S. zeamais. A menor porcentagem de insetos emergidos até a 2 a contagem - que revela um alongamento do ciclo, pode ser atribuída a uma dificul dade inicial do gorgulho para fazer a postura.

No Quadro 4 são comparadas as médias de cada parâmetro para ti pos de grãos dentro de cada nível de infestação. O nível de infestação de 10 insetos em $20 \mathrm{~g}$ de grãos foi o que melhor discriminou os demais tratamentos. Neste nível de infestação, o número total de insetos emer gidos, Indice de emergância e porcentagem de perda de peso, foram menores nos grãos com gluma. No entanto, quando o nível de infestação pas 
QUADRo 1 - Resultados da análise de variância representados pelos quadrados médios, do peso médio e do número total de insetos emergidos, do índice de emergência e das porcentagens ce perda de peso de grãos e do número de insetos emergidos em cada parcela nas duas pri meiras contagens (de quatro realizadas) cujas mëdias estão apresentadas nos Quadros 2 a 6. Piracicaba, SP - 1976.

\begin{tabular}{|c|c|c|c|c|c|c|}
\hline \multirow{2}{*}{$\begin{array}{l}\text { Causa al } \\
\text { da } \\
\text { Variaçäo }\end{array}$} & \multirow[b]{2}{*}{ G.L. } & \multicolumn{5}{|c|}{ QUADRADO MEDIO } \\
\hline & & $\begin{array}{l}\text { Peso médio } \\
\text { dos insetos }\end{array}$ & $\begin{array}{l}\text { Nọ total } \mathrm{b} / \\
\text { de insetos } \\
\text { emergidos }\end{array}$ & $\begin{array}{l}\text { Indice } \\
\text { de emer } \\
\text { gência }\end{array}$ & $\begin{array}{l}\text { Porcentagem }{ }^{\text {c/ }} \\
\text { de perda de } \\
\text { peso }\end{array}$ & $\begin{array}{l}\% \text { de emergenciacl } \\
\left(1^{a}+2_{-}^{a} \text { contagem }\right)\end{array}$ \\
\hline$A(n, i n f)$. & 3 & $16,89 *$ & $1.652,60 *$ & $57,49 *$ & $7.766,04 *$ & $8.390,33 *$ \\
\hline B (tipo grão) & 2 & $0,71 *$ & $18,67 *$ & $1,49 *$ & $206,91 *$ & $125,69 *$ \\
\hline C (genōtipos) & 1 & 0,03 & 4,11 & 0,38 & 2,13 & $1.015,39 *$ \\
\hline$A \times B$ & 6 & $0,08 *$ & $13,52 \%$ & $0,93 \%$ & $70,73 *$ & 27,23 \\
\hline$A \times C$ & 3 & 0,01 & 3,90 & 0,39 & $51,57 *$ & $138,29 *$ \\
\hline$B \times C$ & 2 & 0,00 & 10,68 & 0,35 & 13,79 & 34,61 \\
\hline AI. $B_{1}$ & 3 & $6,41 *$ & $535,00 *$ & $12,67 *$ & $2.215,66 *$ & $2.421,94 *$ \\
\hline$A T \cdot B 2$ & 3 & $6,44 *$ & $592,76 *$ & $\quad 22,75 *$ & $3.120,62 *$ & $3.057,19 *$ \\
\hline AI. $B_{3}$ & 3 & $4,20 *$ & $551,89 *$ & $23,94 *$ & $2.571,22 *$ & $2.965,66^{\star}$ \\
\hline BI. $A_{1}$ & 2 & 0,00 & 0,00 & 0,00 & 1,82 & 0,00 \\
\hline BI. $A 2$ & 2 & $0,25 *$ & $37,82 *$ & $3,70 *$ & $152,70 *$ & $=135,32 *$ \\
\hline BI. $A_{3}$ & 2 & $0,35 *$ & 15,21 & 0,49 & $170,99 *$ & $12,82 *$ \\
\hline BI. A4 & 2 & $0,36^{*}$ & 6,21 & 0,10 & $93,58^{*}$ & 59,23 \\
\hline AI. $C_{l}$ & 3 & $8,19 *$ & $834,09 *$ & $32,23 *$ & $3.606,68^{*}$ & $3.217,88^{*}$ \\
\hline AI, $C_{2}$ & 3 & $8,71 *$ & $822,41^{*}$ & $25,66 *$ & $4.210,93 *$ & $5.310,75 *$ \\
\hline CI. $A_{1}$ & 1 & 0,00 & 0,00 & 0,00 & 0,00 & 0,00 \\
\hline $\mathrm{CI} \cdot \mathrm{A}_{2}$ & 1 & $0,05 *$ & 15,79 & 1,54 & $83,20 *$ & $203,95^{\star}$ \\
\hline $\mathrm{CI} . \mathrm{A}_{3}$ & 1 & 0,01 & 0,01 & 0,00 & 27,10 & $545,83 *$ \\
\hline $\mathrm{CI} . \mathrm{A}_{4}$ & 1 & 0,00 & 0,00 & 0,00 & 46,53 & $680,50^{x}$ \\
\hline BI. $C_{1}$ & 2 & $0,31 *$ & 11,62 & 0,75 & $83,46 *$ & 26,43 \\
\hline $\mathrm{BI} \cdot \mathrm{C}_{2}$ & 2 & $0,40 *$ & $17,72^{\star}$ & $1,08 *$ & $137,23 *$ & $133,88 *$ \\
\hline$C I, B_{1}$ & 1 & 0,02 & 7,30 & 0,31 & 0,88 & 149,17 \\
\hline $\mathrm{CI} \cdot \mathrm{B}_{2}$ & 1 & 0,01 & 11,50 & 0,66 & 26,12 & $363,04 *$ \\
\hline $\mathrm{CI} \cdot \mathrm{B}_{3}$ & 1 & 0,00 & 6,67 & 0,09 & 2,70 & $572,42 \star$ \\
\hline$A \times B \times C$ & 6 & & & & $44,26 *$ & - \\
\hline Trat. & 17 & 2,29 & $223,26 *$ & 8,01 & $1.068,97$ & $1.183,06$ \\
\hline Resíduo & 54 & 0,01 & 5,22 & 0,24 & 17,52 & 33,96 \\
\hline Total & 71 & & & & & \\
\hline $\begin{array}{l}\text { a) A, B e C rep } \\
\text { grãos (glum } \\
\text { b/ Dados trans } \\
\frac{c}{\bar{k} / \text { Dados trans }} \text { Significati }\end{array}$ & $\begin{array}{l}\text { present } \\
\text { as, int } \\
\text { cormado } \\
\text { Eormado } \\
\text { vo ao }\end{array}$ & $\begin{array}{l}\text { ros e quebrad } \\
\text { em } \sqrt{x+0,5} \\
\text { em arc sen } \\
\text { el de } 5 \% \text { de } p\end{array}$ & $\begin{array}{l}\text { e, nível de } \\
\text { e genotip } \\
\text { T100. }\end{array}$ & $\begin{array}{l}\text { e infestação } \\
\text { pos (Cont-75 }\end{array}$ & $\begin{array}{l}(0,10,30 \text { e } 60 \\
\left.\text { e DK } E_{57}\right)\end{array}$ & asetos), \\
\hline
\end{tabular}


QUADRO 2 - Médias de quinze repetições, do peso mëdio e número total de insetos emergidos, do in dice de emergência e das porcentagens de perda de peso dos grãos e do número de inse tos emergidos nas duas primeiras contagens (de quatro realizadas), quando se comparou apenas o efeito dos níveis de infestação. Piracicaba, SP - 1976.

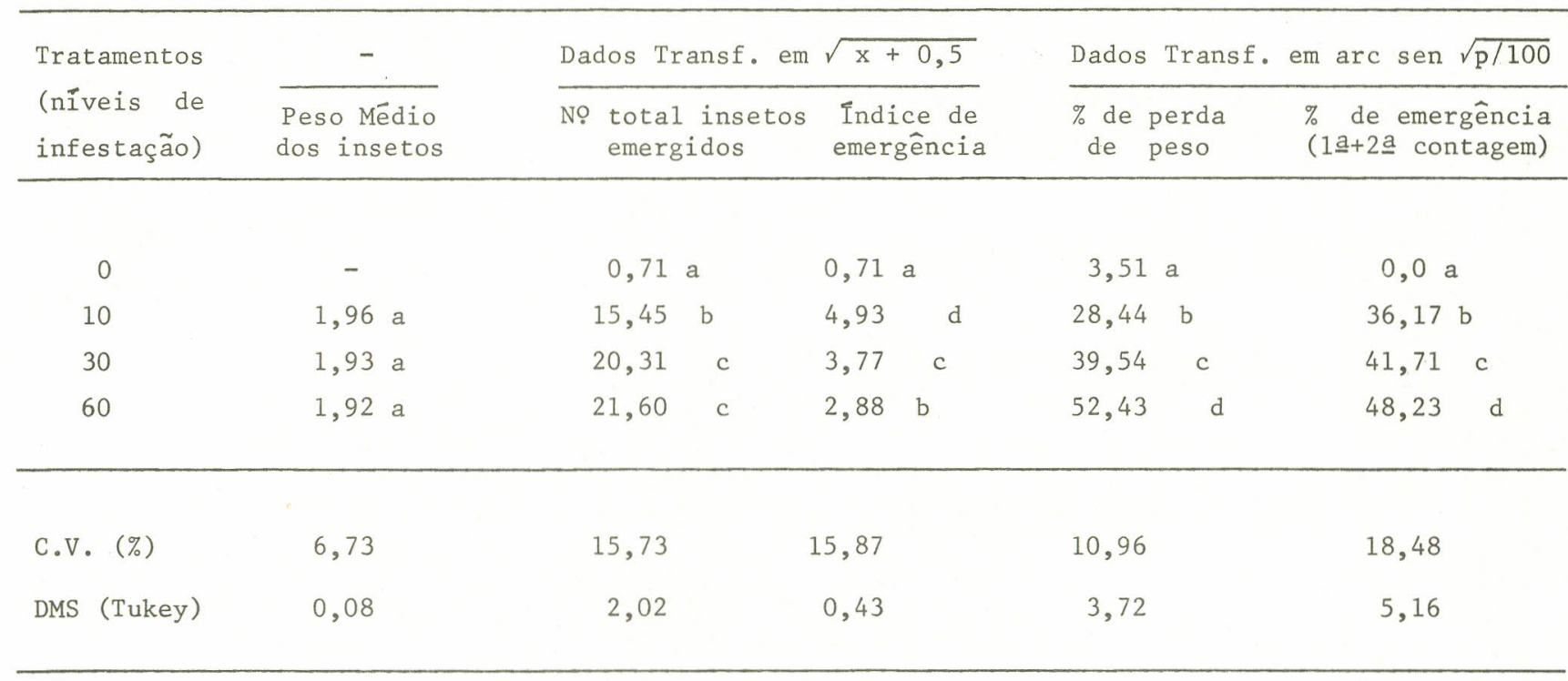

ef Médias seguidas de mesma letra não diferem entre si ao nível de $5 \%$ de probabilidade pelo teste de Tukey, dentro de cada coluna. 
QUADRO 3 - Médias de quinze repetições, do peso mëdio e nümero total de insetos emergidos, do índi ce de emergência e das porcentagens de perda de peso dos grãos e do numero de insetos emergidos nas duas primeiras contagens (de quatro realizadas), quando se comparou apenas o efeito dos tipos de grãos. Piracicaba, SP - 1976.

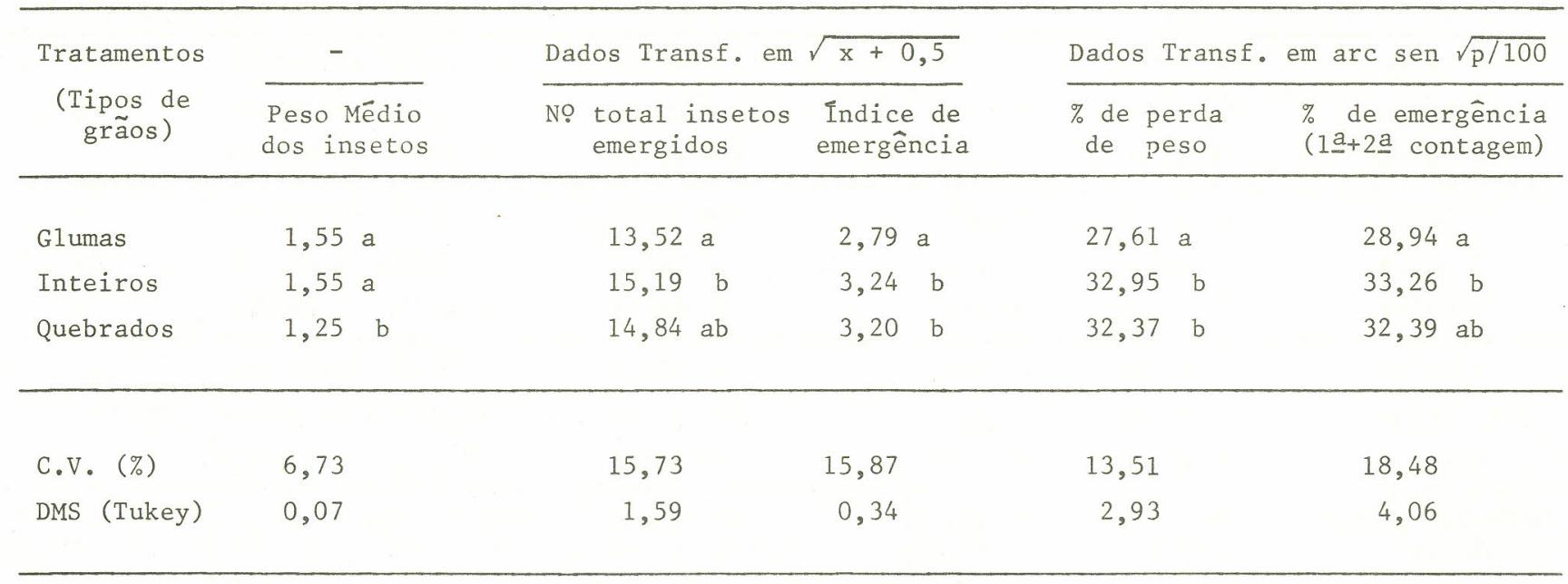

d/ Mëdias seguidas de mesma letra não diferem entre si ao nível de 5\% de probabilidade pelo teste de Tukey, dentro de cada coluna. 
QUADRO 4 - Médias de seis repetições, do peso médio e número total de insetos emergidos, do Indice de emergência e das porcentagens de perda de peso dos grãos e do número de insetos emer gidos nas duas primeiras contagens (de quatro realizadas), quando se comparou o efeito dos tipos de grãos dentro de cada nível de infestação. Piracicaba, SP - 1976.

\begin{tabular}{|c|c|c|c|c|c|c|c|}
\hline \multicolumn{2}{|c|}{ Tratamentos } & - & \multicolumn{3}{|c|}{ Dados Transf. em $\sqrt{x+0,5}$} & \multicolumn{2}{|c|}{ Dados Transf. em arc sen $\sqrt{\mathrm{P} / 100}$} \\
\hline $\begin{array}{l}\text { Nível de } \\
\text { infestação }\end{array}$ & $\underset{\text { grão }}{\text { Tipos de }}$ & $\begin{array}{l}\text { Peso médio } \\
\text { dos insetos }\end{array}$ & № & $\begin{array}{l}\text { total insetos } \\
\text { emergidos }\end{array}$ & $\begin{array}{l}\text { Indice de } \\
\text { emergência. }\end{array}$ & $\begin{array}{l}\% \text { de perda } \\
\text { de peso }\end{array}$ & $\begin{array}{l}\% \text { de emergência } \\
(1 \underline{a}+2 \underline{a} \text { contagem })\end{array}$ \\
\hline & Glumas & 2,07 a & & 12,56 a & $4,03 \mathrm{a}$ & 22,88 a & 31,09 a \\
\hline \multirow[t]{3}{*}{10} & Inteiros & 2,09 a & & $16,72 \quad b$ & $5,33 \quad b$ & $29,72 \quad b$ & $40,50 \quad b$ \\
\hline & Quebrados & 1,72 b & & $17,07 \quad b$ & $5,44 \quad b$ & $32,73 \quad b$ & 36,93 a \\
\hline & Glumas & 2,08 a & & 18,48 a & 3,45 a & 33,42 a & $40,04 a$ \\
\hline \multirow[t]{3}{*}{30} & Inteiros & $2,05 \mathrm{a}$ & & 21,31 a & 3,95 a & $42,02 \quad b$ & 42,34 a \\
\hline & Quebrados & $1,65 \mathrm{~b}$ & & 21,15 a & 3,92 a & $43,20 \quad b$ & 42,76 a \\
\hline & Glumas & 2,05 a & & 22,34 a & 2,97 a & 49,99 a & 44,61 a \\
\hline \multirow[t]{2}{*}{60} & Inteiros & 2,07 a & & 22,03 a & 2,95 a & $56,99 \quad \mathrm{~b}$ & 50,22 a \\
\hline & Quebrados & $1,64 \mathrm{~b}$ & & 20,44 a & 2,73 a & 50,31 a & 49,87 a \\
\hline C.V. (\%) & & 6,73 & & 15,73 & 15,87 & 13,51 & 18,48 \\
\hline DMS (Tukey) & & 0,14 & & 3,18 & 0,68 & 5,85 & 8,12 \\
\hline
\end{tabular}

d/ Médias seguidas de mesma letra não diferem entre si ao nîvel de $5 \%$ de probabilidade pelo teste de Tukey, dentro de cada coluna, para cada tipo de grão. 
QUADRO 5 - Médias de doze repetições, do peso médio e número total de insetos emergidos, do Indice de emergência e das porcentagens de perda de peso dos grãos e do número de insetos emer gidos nas duas primeiras contagens (de quatro realizadas), quando se comparou o efeito dos tipos de grãos dentro de cada genótipo. Piracicaba, SP - 1976.

\begin{tabular}{|c|c|c|c|c|c|c|c|}
\hline \multicolumn{2}{|c|}{ Tratamentos } & - & \multicolumn{3}{|c|}{ Dados Transf. em $\sqrt{x+0,5}$} & \multicolumn{2}{|c|}{ Dados Transf.em arc sen $\sqrt{\mathrm{P} / 100}$} \\
\hline Genötipos & $\begin{array}{l}\text { Tipos de } \\
\text { grãos }\end{array}$ & $\begin{array}{l}\text { Peso médio } \\
\text { dos insetos }\end{array}$ & Nọ & $\begin{array}{l}\text { total insetos } \\
\text { emergidos }\end{array}$ & $\begin{array}{l}\text { Indice de } \\
\text { emergência }\end{array}$ & $\begin{array}{l}\% \text { de perda } \\
\text { de peso }\end{array}$ & $\begin{array}{l}\% \text { de emergencia } \\
(1 \underline{a}+2 \underline{a} \text { contagem })\end{array}$ \\
\hline \multirow{3}{*}{ Cont -75} & Glumas & 1,52 a & & 14,07 a & 2,90 a & 27,80 a & $26,44 a$ \\
\hline & Inteiros & 1,53 a & & 15,89 a & 3,40 a & $31,92 \mathrm{ab}$ & 29,37 a \\
\hline & Quebrados & $1,24 \quad b$ & & 14,32 a & 3,14 a & $32,71 \quad b$ & 27,51 a \\
\hline \multirow{3}{*}{$\mathrm{DK}_{57}$} & Glumas & 1,58 a & & $12,97 \mathrm{a}$ & 2,67 a & 27,42 a & 31,43 a \\
\hline & Inteiros & 1,58 a & & $14,50 \mathrm{ab}$ & $3,07 a b$ & $34,00 \quad b$ & $37,15 \quad b$ \\
\hline & Quebrados & $1,26 \quad b$ & & $15,37 \quad b$ & $3,26 \quad b$ & $32,04 \quad b$ & $37,27 \quad b$ \\
\hline C.V. (\%) & & 6,73 & & 15,73 & 15,87 & 10,96 & 18,48 \\
\hline DMS (Tukey) & & 0,10 & & 2,23 & 0,48 & 4,14 & 5,74 \\
\hline
\end{tabular}

d Médias seguidas de mesma letra não diferem entre si ao nỉvel de $5 \%$ de probabilidade pelo teste de Tukey, dentro de cada coluna e genótipo. 
sou para 30 e 60 insetos, a diferença entre os grãos com gluma e quebra dos desapareceu. Como os grãos quebrados em todos os níveis de infesta ção produzem insetos mais leves, é possível inferir que sob as infesta ções mais altas, os grãos quebrados foram menos suscetíveis ao $S$. zea mais.

Como pode ser observado no Quadro 5, o efeito do tipo de grão dentro de cada genótipo foi mais evidente no hỉbrido, onde todos parâme tros apresentaram diferenças significativas, portanto o genótipo afeta $\bar{a}$ resposta dos insetos quando confinados em cada tipo de grão (com gluma, inteiro ou quebrado).

No Quadro 6 se comparou o efeito dos genótipos quando o nível de infestação foi de apenas 10 insetos. Embora o hỉbrido DK $\mathrm{E}_{57}$ tenha produzido insetos mais pesados e num período mais curto em ${ }^{57}$ relação a linhagem Cont-75, apresentou um menor índice de emergência de insetos e menor porcentagem de perda de peso, comportando-se assim menos susce tível que a linhagem.

QUADRO 6 - Mëdias de nove repetições, do peso mëdio dos insetos emer gidos, do indice de emergência e das porcentagens de perdá de peso dos grãos e do número de insetos emergidos nas duas primeiras contagens (de quatro realizadas), quando se com parou os genótipos no nível de infestação de dez insetos. Piracicaba, SP - 1976.

\begin{tabular}{cccccc}
\hline & Peso médio & Indice & Porcentagem & Porcentagem de \\
Tratamentos & dos & de & de & perda & emergência (1á+ \\
(Genótipos) & insetos & emergência & de peso & $2_{-}^{\text {a }}$ contagem) \\
\hline
\end{tabular}

\begin{tabular}{|c|c|c|c|c|}
\hline Cont -75 & 1,91 a & 5,22 a & 30,59 a & 32,81 a \\
\hline $\mathrm{DK} \mathrm{E}_{57}$ & $2,01 \quad b$ & $4,64 \mathrm{~b}$ & $26,29 \quad b$ & 39,54 \\
\hline
\end{tabular}

$\begin{array}{lrrrr}\text { C.V. (\%) } & 6,73 & 15,87 & 13,51 & 18,48 \\ \text { DMS (Tukey) } & 0,09 & 0,46 & 3,97 & 5,51\end{array}$

c]

Médias seguidas de mesma letra não diferem entre si ao nĩve1 de $5 \%$

d) de probabilidade pelo teste de Tukey, dentro de cada coluna. Dados transformados em $\sqrt{x+0,5}$

el Dados transformados em arc sen $\sqrt{\mathrm{P} / 100}$. 


\section{CONCLUSÕES}

Com base nos resultados apresentados e para as condições estuda das pode-se concluir:

1. O nỉvel de infestação não afeta o peso médio dos insetos des cendentes.

2. Quando se infesta $20 \mathrm{~g}$ de grãos de sorgo com 30 ou 60 insetos jā ocorre uma alta competição intraespecífica em relação à infesta ção com 10 insetos.

3. Quando se eleva o nível de infestação de 10 insetos em $20 \mathrm{~g}$ de sorgo para 30 ou 60, ocorre um incremento na perda de peso, mas o da no atribuỉdo a cada inseto (perda de peso dos grãos/no insetos usados na infestação) diminui.

4. Dentro dos limites de infestação estudados, aumentando-se o nỉvel de infestação hä uma sensível redução do ciclo dos gorgulhos.

5. Os grãos quebrados produzem insetos mais leves que os grãos com gluma ou inteiros.

6. Em condições de baixa infestação (10 insetos) os grãos com gluma são menos suscetĩveis aos gorgulhos que os outros dois tipos, mas em condições de altas infestações (60 insetos) os grãos quebrados são menos suscetíveis.

7. 0 nîvel de infestação de 10 insetos em $20 \mathrm{~g}$ de grãos de sor go è o que melhor discrimina os demais tratamentos.

8. O genótipo afeta a resposta dos insetos confinados nos dife rentes tipos de grãos (com gluma, inteiro limpo e quebrado).

9. O hỉbrido Dekalb $E_{57}$ é menos suscetível que a linhagem Cont-75 ao $S$. zeamais.

\section{LITERATURA CITADA}

DAVEY, P.M. The susceptibility of sorghum to attack by the weevil Sito philus omyzae (L.). Bull. ent. Res., 56(2):287-297, 1965.

DOGGETT, H. The breeding of sorghum in East Africa. I. Weevil resis tance in sorghum grains. Emp. J. exp. Agric., 25(97):1-9, 1957.

- The breeding of sorghum in East Africa. II. The breeding of weevil-resistant varieties. Emp. J. exp. Agric., 26(101):37-46, 1958.

KIRITANE, K. Biological studies on the Sitophilus Complex (Coleopte ra - Curculionidae) in Japan. J. stored Prod. Res., 1:169-176, 1965.

LEFEVRE, P.C. Etude de CaZandra oryzae L. sur sorgho (Sorghum vulgare Brot.). Bull. agrie. Congo belge, 44(5):1001-1046, 1953.

MORRISON, E.O. The effect of particle size of sorghum grain on develop ment of the weevil Sitophizus zeamais Motsh. J. econ. Ent., 53(3): $390-391,1964$.

PARKIN, E.A. Stored Entomology (The assessiment and reduction of losses caused by insects to estored foodstuffs). Ann. Rev. Entomol. 1:223$240,1956$.

REDDY, D.B. Influence of sound kernels compared with halved kernels of 
wheat upon oviposition of the rice weevil. J.econ. Ent., 43(3):390$391,1950$.

RITCHIE, A.H. Entomological Report. Tanganyka Terr. Rept. Dept. Agric, Dar-es-Salaan, p. 33-36, 1925/26. Apud Rev. appl. Ent., séries A: Agricultura1, London, 15:325-327, 1927. (Abstract s.n.).

ROGERS, R.R. \& MILLS, R.B. Evaluation of a world sorghum collection for resistance to the maize weevil, Sitophilus zeamais Motsch. (Co leoptera - Curculionidae). J. Kansas ent. Soc., 47(1):36-41, 1974. ROSSETTO, C.J. Resistência de milho à pragas da espiga, Helicoverpa zea (Boddie), Sitophilus zeamais Motschulsky e Sitotroga cerealelza (Olivier). Piracicaba, ESALQ-USP. 144 p., 1972. (Tese de Doutora mento).

ROSSETTO, C.J.; BANZATTO, N.V.; CARVALHO, R.P.L.; AZZINI, L.E.; LARA, F.M. Pragas do sorgo em São Paulo. In: SIMPŐSIO INTERAMERICANO DE SORGO 1, Anais, Brasīlia, Ministério da Agricultura, p. 217-225, 1972 .

RUSSELL, M.P. Field infestation of corn in Indiana by the angoumois grain month and a rice weevil. J. econ. Ent., 55(5):814-815, 1962 a.

RUSSELL, M.P. Effects of sorghum varieties on the lesser rice weevil. Sitophilus omyae. (L.). I. Oviposition, immature mortality and size of adults. Ann. ent. Soc. Amer., 55(6):678-685, 1962 b.

RUSSELL, M.P. Effects of sorghum varieties on the lesser rice weevil, Sithophilus oryzae (L。). J. stored Prod. Res., 2:75-79, 1966.

SAMUEL, C.K. \& CHATTERJI, S. Studies on the varietāl resistance and susceptibility of "JOWAR" (Andropogan sorghum) to storage pests of India. Indian J. ent., 15(3):225-239, 1953. Apud Rev. appl. Ent., series A: Agricultura1, London, 43(5):152, 1955, (Abstract s.n).

SILVEIRA NETO, S.; NAKANO, O.; BARBTIN, D.; VILLA NOVA, N.A. Mcnual de Ecologia dos Insetos. São Paulo, Editora Agronômica Ceres. 419 p. 1976.

SINHA, R.N. Multiplication of some stored-product insects on varieties of wheat, oats, and barley. J. econ. Ent., 64(1):98-102, 1971.

TEOTIA, T.P.S. \& SINGH, V.S. On the oviposition behaviour and develop ment of Sitophilus oryzae (L.) in various natural foods. Indian $J_{\text {. }}$ ent., 30(2):119-124, 1968. Apud Rev. appl. Ent., series A: Agricu1 tural, London, 58(8):542, 1970. (Abstract 2.244).

YADAV, T.D.; SIRCAR, P.; JOTWANI, M.G. Studies on insect damage and germination of seeds III. Germination of wheat, jowar and maize seeds damage by the developing grubs of Sitophilus oryzae (L.) and Rhizophertha dominica (F.). Indian J. ent., 30(1):83-84, 1968. Apud Rev. appl. Ent., series A: Agricultural, London, 58(2):84, 1970. (Abstract 308).

\section{RESUMO}

Os grãos de sorgo são infestados pelas pragas de grãos armaze nados. Dentre os gorgulhos que atacam os grãos de cereais no Brasil, destaca-se o Sitophilus zeamais Motschulsky, 1855 pela sua maior distri buição, constituindo assim numa importante praga do sorgo. o sorgo grä nífero depois de colhido e trilhado a massa de grãos apresenta três ca- 
tegorias distintas: grãos com gluma, inteiros limpos e quebrados, cujas proporções dependem da regulagem da máquina utilizada na operação.

Procurou-se estimar, em laboratório, os danos experimentais cau sados pelo S. zecmais, confinando-se $0,10,30$ e 60 gorgulhos adultos em $20 \mathrm{~g}$ de grãos de cada categoria, por trinta dias, utilizando-se como substrato um híbrido - Dekalb E57 e uma linhagem - Contibrasil - 75.

Verificou-se que os grãos inteiros foram mais danificados em todos os níveis de infestação estudados. Em condições de baixa infesta ção, os grãos com gluma foram menos atacados que os grãos quebrados, mas em condições de alta infestação os grãos quebrados perderam menos peso e produziram insetos mais leves. 